\title{
Role of Magnetic Resonant Imaging in Laryngeal Cancer
}

\author{
NAGHAM N. OMAR, M.D.*; ALAA K. ABD EL-HALEEM, M.D.**; SHERIF M. ABD EL-AL, M.D.* and \\ DINA G.E. MOHAMED, M.Sc.*
}

The Departments of Radiodiagnosis* and Otolaryngology**, Faculty of Medicine, Assiut University

\begin{abstract}
Background: MRI plays a significant complementary role to clinical endoscopy in pre therapeutic staging of laryngeal squamous cell carcinoma.

Aim of Study: To evaluate role of MRI in laryngeal cancer, detect its accuracy, specificity in staging, differentiates post irradiation from recurrence.

Patients and Methods: The study was conducted at the Department of Radio Diagnosis, University of Assiut, Egypt. From September 2015 to April 2016, 40 male patients, aged 50-85 years (median 67.5 years), the study comprised patients with suspected or known laryngeal cancer, the symptomatology was predominantly characterized by hoarseness and cough. The study was performed with the approval of all patients give their informed consent to the study.

Results: MRI shows a sensitivity of $100 \%$ and a specificity of $97 \%$ in assessing areas such as paraglottic space, anterior commissure, thyroid, and arytenoid cartilages with various indications for conservative surgery. The accuracy of MRI In T1 stage was $85 \%$ and for laryngoscopy was $85.7 \%$, the accuracy of MRI in T2 stage was $85 \%$ and for laryngoscopy was $80 \%$, the accuracy of MRI in T3 stage was $95 \%$ and for laryngoscopy was $75 \%$, the accuracy of MRI in T4 stage was $100 \%$ and for laryngoscopy was $80 \%$, while for the determination of cartilaginous invasion MR showed a sensitivity $38.9 \%$ specificity $100 \%$, accuracy $45 \%$.

Conclusion: Despite some limitations, including the small number of laryngeal carcinomas included, DWI may detect changes in tumor size and shape before they are visible by laryngoscopy. The ADC values were lower for patients with laryngeal carcinoma than for those with laryngeal precancerous lesions. The proposed cutoff for the ADC may help to distinguish laryngeal carcinomas from laryngeal precancerous lesions.
\end{abstract}

Key Words: Laryngeal cancer - Magnetic resonance imaging (MRI) - Diffusion weighted imaging (DWI).

Correspondence to: Dr. Nagham N. Omar, The Department of Radiodiagnosis, Faculty of Medicine, Assiut University

\section{Introduction}

LARYNGEAL cancer represents $4.5 \%$ of all malignancies and $28 \%$ of cancers of the upper aero digestive tract. Ninety percent of the malignant tumors of the larynx are composed of squamous cell carcinomas with different distributions of prevalence based on the specific subside affected (glottic, supraglottic and subglottic site). Laryngeal cancer comprises $1-5 \%$ of all malignancies diagnosed annually. Approximately $67 \%$ of laryngeal carcinomas are glottic; $1-2 \%$ is subglottic. The prevalence and types of laryngeal cancer can be explained to some degree by the epithelial lining in that area [1]. It is necessary to stage the laryngeal cancer in a correct way in order to choose the most correct therapeutic approach based on the available options from organ preservation strategies (radiotherapy, partial resection/cordectomy with $\mathrm{CO} 2$ laser and conservative partial reconstructive surgery) to demolitive surgery. This is especially true forglottic tumors at an early stage of disease, which have demonstrated high rates of local control with organ preservation techniques such as radiotherapy (84\%-95\%) and partial resections (85\%-100\%) [2] It is important to evaluate precisely the extent of tumor preoperatively to plan the correct procedure to assure clear margins to the patient to avoid local recurrence. CT and MR imaging are routinely used to differentiate between limited and gross cartilage invasion. Some studies have shown that MRI is more sensitive than CT in the evaluation of cartilage tumor invasion. However, cartilage invasion is sometimes overestimated. The overestimation of the magnetic resonance protocol is probably related to the presence of peritumoral inflammation, which amplifies/inflates the boundaries of abnormal tis-

\section{Abbreviations:}

MRI: Magnetic Resonance Imaging. DWI: Diffusion Weighted Imaging. 
sues [3]. Advances in Magnetic Resonance Imaging (MRI) and Computed Tomography (CT) scanning have improved the ability to visualize the larynx. MRI is better than CT scanning at delineation of soft tissue involvement and has the capability of multiplanar high-resolution imaging MRI, however, has limitations. Because MRI cannot image solidly calcified structures, cartilaginous and bony imaging has been difficult. Furthermore, acquisition time in MRI is longer than in other radiologic techniques, most notably CT scanning. These challenges are complicated further by the degradation of images secondary to motion artifacts from swallowing, breathing, and carotid artery pulsations. Newer, faster MRI techniques have overcome some of these barriers, thus permitting assessment of deep laryngeal structures for accurate evaluation and staging of laryngeal disease. This allows for proper surgical management or conservative therapy. MRI is contraindicated in patients with cardiac pacemakers, ferromagnetic cerebral aneurysm clips, and metallic cochlear implants. Sedation may be necessary for claustrophobic patients because imaging is performed by placing the patient in the tight confines of the bore of a super conducting magnet [4]. DWI of the head and neck has commonly been done with a $1.5-\mathrm{T}$ scanner. The sensitivity, specificity, and accuracy were 100.0, 88.2, and $96.0 \%$, respectively. Althoughthe diagnosis was not improved statistically compared with laryngoscopy, DWI may detect changes in tumor size and shape before they are visible to the naked eye. Laryngoscopy has an advantage in judging motion in the larynx, but it does not detect changes under the mucosa or the multifocal nature of tumors [5].

Aim of work: To evaluate role of MRI in laryngeal cancer, detect its accuracy, specificity in staging, differentiates post irradiation from recurrence.

\section{Material and Methods}

Institutional review board approval and written informed consent forms were obtained for this study, the study was conducted at the Department of Radio Diagnosis, University of Assiut, Egypt From September 2015 to April 2016, 40 male patients, aged 50-85 years (mean, 67.5 years). The study comprised patients with suspected or known laryngeal cancer; the symptomatology was predominantly characterized by hoarseness and cough. The study was performed with the approval of all patients give their informed consent to the study. All patients were subjected to a diagnostic workup including indirect laryngoscopy, MRI and biopsy. In order not to invalidate the results, MRI scans were performed before laryngeal biopsy, so that the images do not prove altered by the presence of peritumoral inflammation. The evaluation of MRI was performed independently by two radiologists who were unaware of the Laryngoscopic features and surgical findings.

Of 40 patients, all were smokers twenty of those patients were newly diagnosed with laryngeal cancer and the remaining twenty had previously undergone surgery and/or chemo radiotherapy for laryngeal cancer. Staging of disease in all patients was clinically assessed according to the 7 th edition of the TNM classification established by the American Joint Committee on Cancer (AJCC) [6]. The $\mathrm{T}$ staging by indirect laryngoscopy classified twelve patients are $\mathrm{T} 1$, eight patients are $\mathrm{T} 2$, and twelve patients are T3 and eight patients are T4. Patients are currently included in a follow-up program including visits every 3 months with video laryngoscopy and radiological examinations such as ultrasound of the neck, chest radiography, CT, and MRI, in agreement with clinical evidence.

Staging by MRI: MR images were obtained with a Philips Achieve 1.5T, MR examinations were performed with an anterior surface neck coil and $\mathrm{T}$ 1-weighted spin echo and $\mathrm{T} 2$ turbo spin echo images in axial and coronal projection, without contrast, Diffusion Weighted Imaging (DWI) and $\mathrm{T} 1 \mathrm{w}$ spin echo sequences with fat saturation were obtained, the number of the sections was 20 for all sequences. The sections were $3-4 \mathrm{~mm}$ of interspace thickness with a $1 \mathrm{~mm}$ intersection gap. The evaluation of cartilage invasion followed the new criteria proposed by Becker et al. The DWI was performed to better discriminate peritumoral edema from neoplastic tissue, but, at present, there are no studies reporting the performance of DWI. The advantage introduced by DWI sequence consists in obtaining information about the cellularity of tissues [7].

\section{Inclusion criteria:}

Patients in different age groups with suspected laryngeal cancerassessed by indirect laryngoscopy were enrolled; the symptomatology was predominantly characterizedby hoarseness and cough and stridor.

\section{Exclusion criteria:}

Any general contra indication for magnetic resonant imaging as cardiac pacemaker, severely ill patients or those withclaustrophobia. 
Table (1): Staging of laryngeal cancer [8]

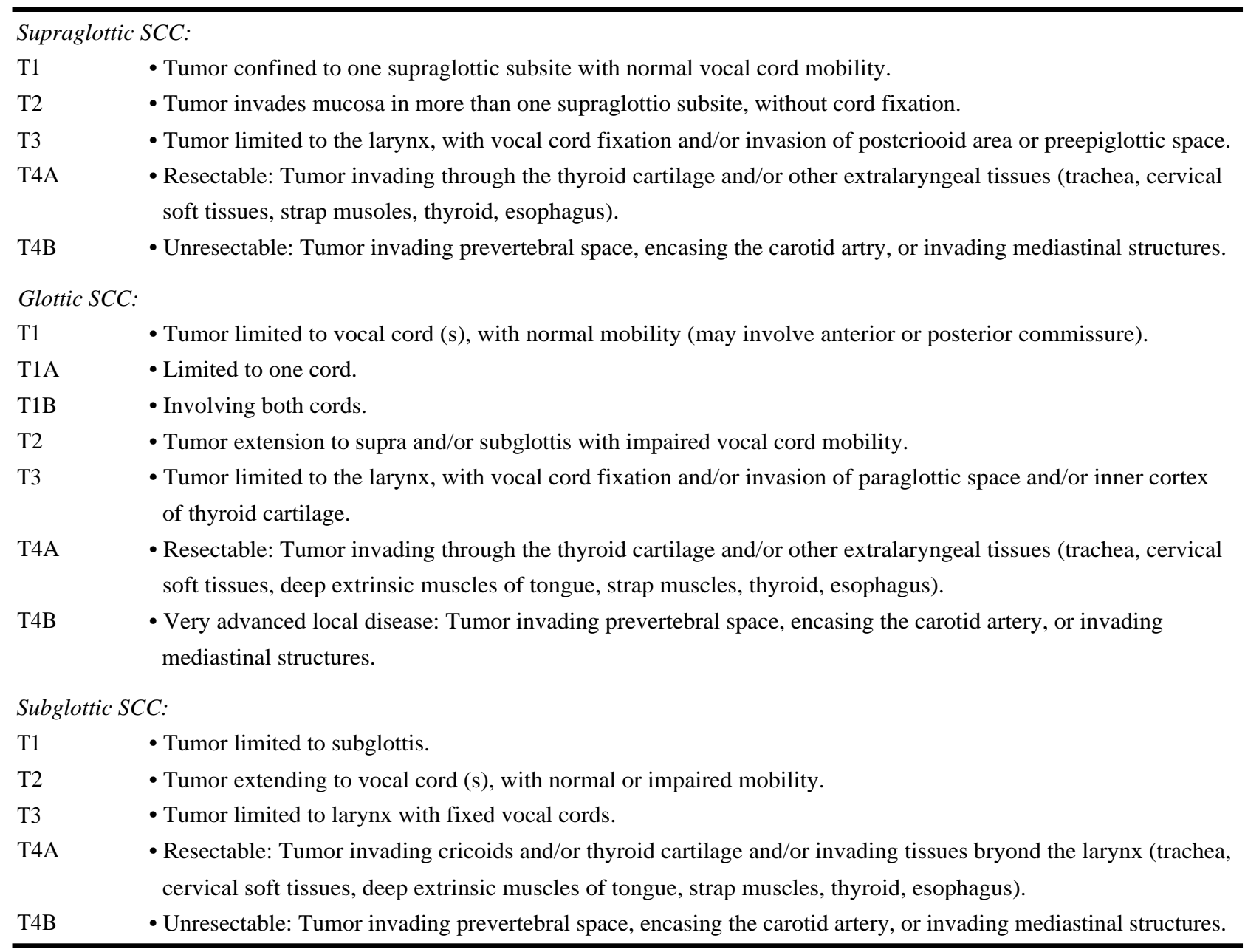

\section{Patients were subjected to the following:}

1- Clinical assessment:

a- Full clinical history.

b- Clinical examination which was performed by the help of the referring physicians.

c- Laryngoscopic examination by ENT specialist.

\section{2- Radiological assessment: Conventional MR} imaging preliminary to the magnetic resonance diffusion examination.

Patient preparations:To acquire an optimal MRI examination adequate patient preparation is as important as the optimization of the technique: Psychological preparation of the patient, confirmation for the absence of any paramagnetic material with patient.

MRI scan protocol: MR examination was performed at (1.5T) super conducting MR imaging (Philips Achieva), the examination was done using surface coils.

\section{Sequences:}

- Sagital spin echo set of images is obtained initially to prescribe the location of axial images.

- Thin (2-4mm) axial T1-weighted (a repetition time (TR) of 500-600ms and echo time (TE) of 8-9ms) images, and T2-weighted (TR of 3000 $\mathrm{ms}$ and TE of $100 \mathrm{~ms}$ ) images with intersection gap $1 \mathrm{~mm}$. Field of View (FOV) is usually 220 to $250 \mathrm{~mm}$ with matrix of $256 \times 256$ for axial images.

Axial T1 \& T2 images extended from hyoid bone (approximately the level of the third cervical vertebra) to the lung apex.

- Coronal T2 \& SPIR images were obtained for evaluation of masses that extended below the cervico-thoracic Junction.

- Diffusion MRI: In addition to conventional techniques, DWI and ADC maps were obtained. Diffusion Magnetic resonance imaging (DW- 
MRI) was carried out on 1.5 tesla super conducting MR imager (Philips Achieva).

Technique of examination: Patients were positioned in supine position and were instructed not to swallow or move during the examination. Circularly polarized surface coil was placed over the neck. A fast scout scan in sagittal, axial, and coronal planes was obtained.

All patients underwent DW-MRIwhich was obtained in axial plane and performed without injection of contrast material. DW-MRI was obtained using a multi-section single shot spin echo EPI sequence (TR/TE/NEX: 3395/100ms/1) with $\mathrm{b}$ values $=400,600,800$ and $1000 \mathrm{~mm}^{2} / \mathrm{s}$.

The diffusion gradients were applied sequentially in the three orthogonal directions. Sections of 2-4mm thickness, inter-slice gap of $1 \mathrm{~mm}$, a 230-
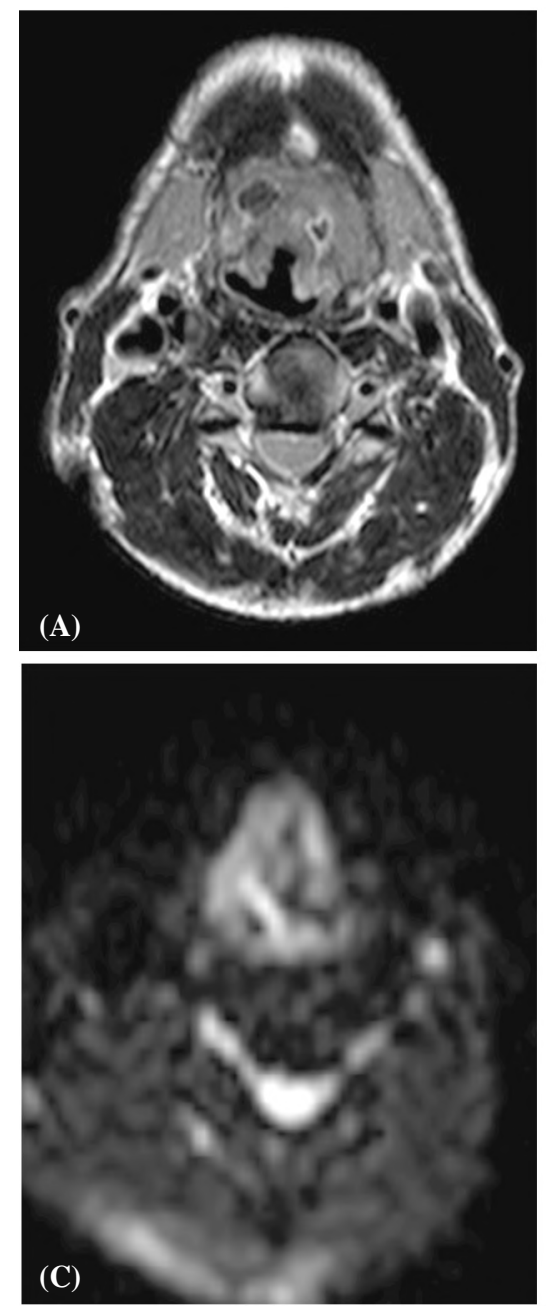

$255 \mathrm{~mm}$ FOV, and a $256 \mathrm{X} 256$ matrix were used with average scan time of $35 \mathrm{~s}$.

\section{Histopathological correlation:}

Histopathological correlation between magnetic resonance diffusion readings and histopathological sections was performed in all cases where punch biopsy was taken by laryngoscope.

\section{Statistical analysis:}

Computer software package SPSS 20 was used in the analysis. For quantitative variables, mean and standard deviation were presented. Frequency and percentages were presented for qualitative variables, sensitivity, specificity; PPV, NPV and accuracy all were calculated for the conventional MRI and for the DWI. $t$-test was used to estimate differences in quantitative variables. $p$-value $<0.05$ is considered to be significant.
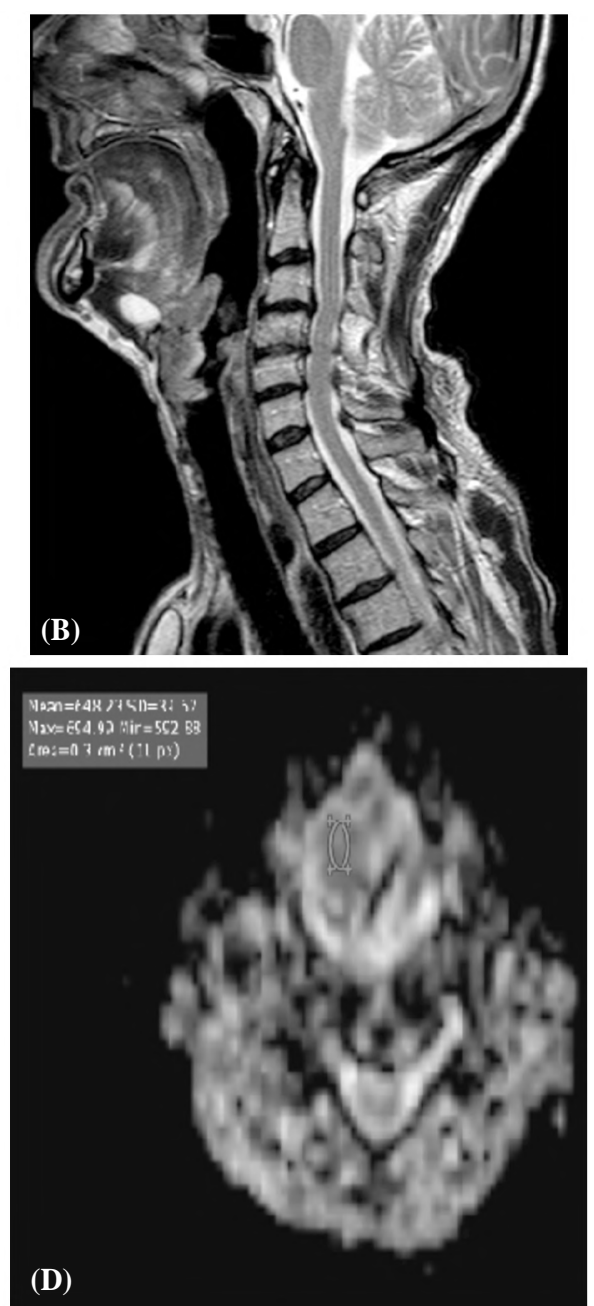

Fig. (1): Axial T2WI and sagittal T2WI through the neck of male patient 58 years old with horsness of voice revealed Supraglottic mass involving the epiglottis, vallecula, ary epiglottic fold, pre epiglottic fat, and both paraglottic fat both false cords right true vocal cord infiltration, coronal T2WI showing the supragloţtic mass. DWI examination: Shows restriction up to b-value of 1000, ADC value $0.64 \mathrm{X}$ $10 \mathrm{~mm} / \mathrm{s}$. Histological examination: Revealed epiglottitis chronic nonspecific inflammation. 

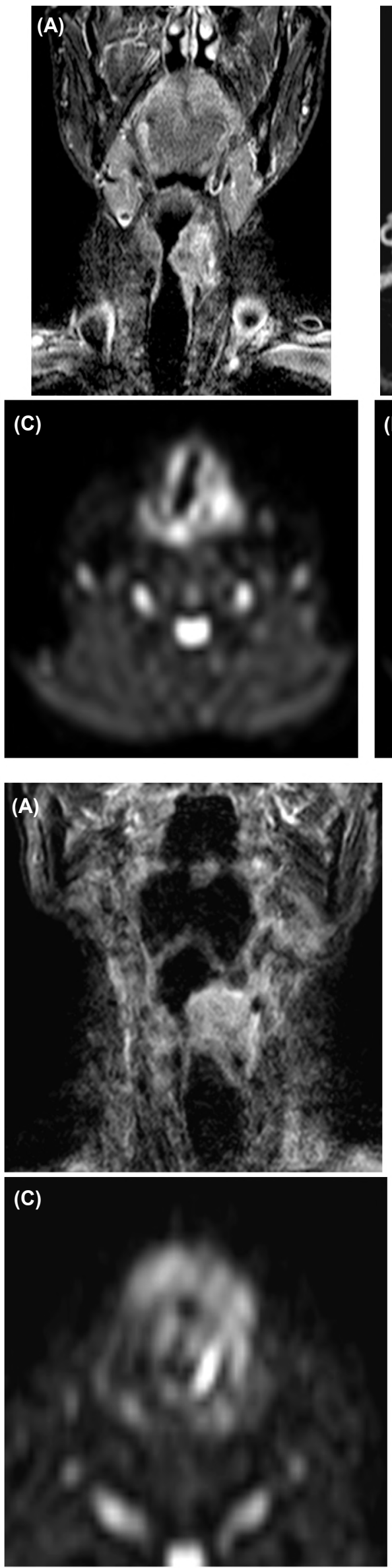
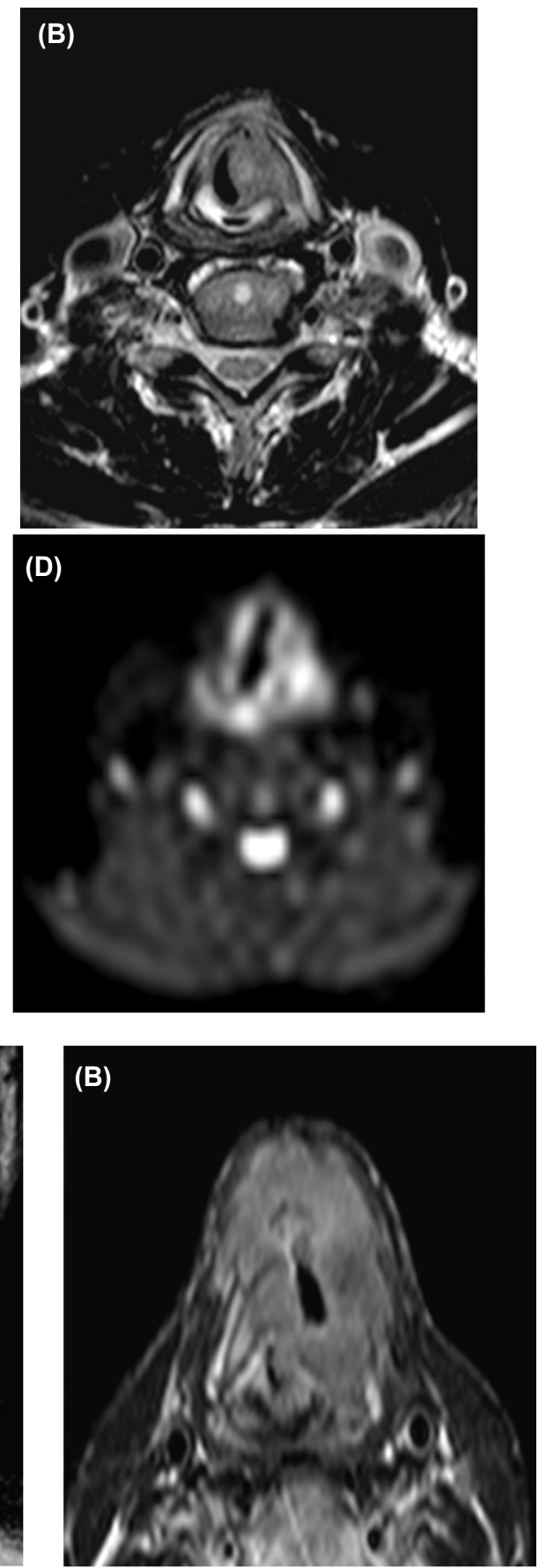

(D)

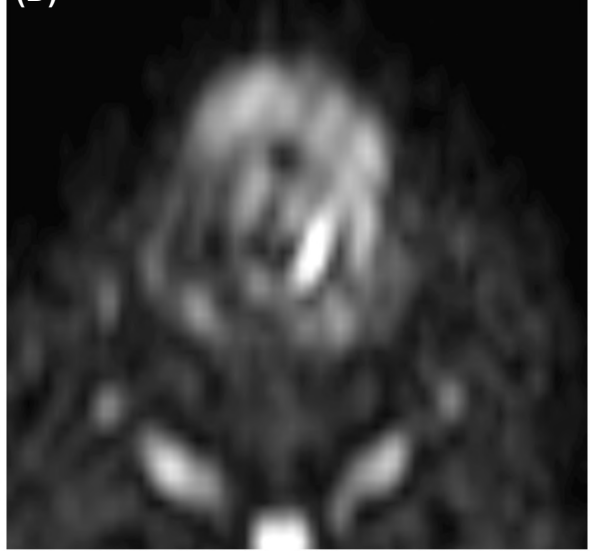

Fig. (2): Male patient aged 60 years complaining of hoarseness of voice. MRI examination: Coronal STIR image of the neck shows left trans glottic mass. Axial T2WI shows hyper intense signal involving the left false cord, left true cord and left sub glottis extension. Histological examination: Grade II-III squamous cell carcinoma. DWI shows restriction with $_{2} \mathrm{ADC}$ value between $0.99 \mathrm{X}$ $10 \mathrm{~mm} / \mathrm{s}$.
Fig. (3): Male patient aged 55 years complaining of hoarseness of voice and long-lasting cough. MRI examination: Coronal STIR revealed left trans glottic mass infiltrating the left para glottic fat spaces, both false cords, both laryngeal ventricles, both true vocal cords, anterior commissure, posterior commissure, lamina of thyroid cartilage and extends to sub cutaneous tissue anteriorly with sub glottic extension. DWI shows restriction with $\mathrm{ADC}_{2}$ value between $0.95 \times 10^{-3} \mathrm{~mm}^{2} / \mathrm{s}$. Histological examination revealed grade II squamous cell carcinoma. 


\section{Results}

Table (2): Descriptive statistics of studied patients.

\begin{tabular}{|c|c|c|}
\hline & No. & $\%$ \\
\hline \multicolumn{3}{|l|}{ Sex: } \\
\hline Male & 40 & 100.0 \\
\hline Female & 0 & 0.0 \\
\hline \multicolumn{3}{|l|}{ Age: } \\
\hline Range & \multicolumn{2}{|c|}{$50-88$} \\
\hline Mean \pm SD & \multicolumn{2}{|c|}{$63.4 \pm 10.5$} \\
\hline \multicolumn{3}{|l|}{ Complaint: } \\
\hline Asphyxia of sudden onset, hoarseness of voice & 2 & 5.0 \\
\hline Hoarseness of voice & 18 & 45.0 \\
\hline Known case of cancer larynx on radio, tracheostomy & 2 & 5.0 \\
\hline Known case of cancer larynx on chemotherapy & 4 & 10.0 \\
\hline Known case of cancer larynx on radiotherapy & 4 & 10.0 \\
\hline Known case of cancer larynx & 6 & 15.0 \\
\hline Known case of cancer larynx on chemo, radio & 2 & 5.0 \\
\hline Left sided neck swelling & 2 & 5.0 \\
\hline \multicolumn{3}{|l|}{ Site: } \\
\hline Bilateral transglottic & 2 & 5.0 \\
\hline extra laryngeal & 2 & 5.0 \\
\hline Lt. glottis & 6 & 15.0 \\
\hline Lt. supraglottic & 2 & 5.0 \\
\hline Lt. transglottic & 8 & 20.0 \\
\hline Rt. Glottis & 8 & 20.0 \\
\hline Rt. Subglottic & 2 & 5.0 \\
\hline Rt. Transglottic & 10 & 25.0 \\
\hline \multicolumn{3}{|l|}{ TNM: } \\
\hline T1N0 & 8 & 20.0 \\
\hline $\mathrm{T} 1 \mathrm{~N} 2$ & 4 & 10.0 \\
\hline T2N0 & 6 & 15.0 \\
\hline $\mathrm{T} 2 \mathrm{~N} 2$ & 2 & 5.0 \\
\hline T3N0 & 2 & 5.0 \\
\hline $\mathrm{T} 3 \mathrm{~N} 1$ & 4 & 10.0 \\
\hline T3N2 & 4 & 10.0 \\
\hline T3N3 & 2 & 5.0 \\
\hline T4N0 & 4 & 10.0 \\
\hline T4N1 & 2 & 5.0 \\
\hline $\mathrm{T} 4 \mathrm{~N} 2$ & 2 & 5.0 \\
\hline \multicolumn{3}{|l|}{ Signal intensity on T2: } \\
\hline Hyper intense & 36 & 90.0 \\
\hline Iso intense & 4 & 10.0 \\
\hline \multicolumn{3}{|l|}{ Cartilage invasion: } \\
\hline Yes & 14 & 35.0 \\
\hline No & 26 & 65.0 \\
\hline \multicolumn{3}{|l|}{ Vessels: } \\
\hline No & 40 & 100.0 \\
\hline \multicolumn{3}{|l|}{ Lymph nodes: } \\
\hline Yes & 18 & 45.0 \\
\hline No & 22 & 55.0 \\
\hline \multicolumn{3}{|l|}{ Pre epiglottic: } \\
\hline Yes & 10 & 25.0 \\
\hline No & 30 & 75.0 \\
\hline \multicolumn{3}{|l|}{ Paraglottic: } \\
\hline Yes & 18 & 45.0 \\
\hline No & 22 & 55.0 \\
\hline \multicolumn{3}{|l|}{ Diffusion: } \\
\hline Restricted & 32 & 80.0 \\
\hline Facilitated & 8 & 20.0 \\
\hline \multicolumn{3}{|l|}{$A D C:$} \\
\hline Range & \multicolumn{2}{|c|}{$0.22-1.2$} \\
\hline Mean \pm SD & 0.7 & $3 \pm 0.24$ \\
\hline Pathology results: & & \\
\hline Malignant & 36 & 90.0 \\
\hline Benign & 4 & 10.0 \\
\hline
\end{tabular}

Table (3): Comparison between malignant and benign as regards patient's age.

\begin{tabular}{|c|c|c|c|c|c|}
\hline & \multicolumn{4}{|c|}{ Pathology results } & \multirow{3}{*}{$\begin{array}{c}p- \\
\text { value }\end{array}$} \\
\hline & \multicolumn{2}{|c|}{ Malignant } & \multicolumn{2}{|c|}{ Benign } & \\
\hline & Mean \pm SD & Range & Mean \pm SD & Range & \\
\hline$\overline{\text { Age }}$ & $64.2 \pm 10.9$ & $50-88$ & $56.5 \pm 1.7$ & $55-58$ & 0.172 \\
\hline
\end{tabular}

Table (4): Comparison between malignant and benign as regards site.

\begin{tabular}{lccccc}
\hline & \multicolumn{4}{c}{ Pathology results } & \multirow{2}{*}{$\begin{array}{c}p \text { - } \\
\text { Site }\end{array}$} \\
\cline { 2 - 4 } & \multicolumn{2}{c}{ Malignant } & \multicolumn{2}{c}{ Benign } & value \\
\cline { 2 - 4 } & No. & $\%$ & No. & $\%$ & \\
\hline Bilateral transglottic & 2 & 5.6 & 0 & 0.0 & $0.001 * *$ \\
Extra laryngeal & 2 & 5.6 & 0 & 0.0 & \\
Lt. glottic & 6 & 16.7 & 0 & 0.0 & \\
Lt. supraglottic & 0 & 0.0 & 2 & 50.0 & \\
Lt. transglottic & 8 & 22.2 & 0 & 0.0 & \\
Rt. glottic & 6 & 16.7 & 2 & 50.0 & \\
Rt. subglottic & 2 & 5.6 & 0 & 0.0 & \\
Rt. transglottic & 10 & 27.8 & 0 & 0.0 & \\
\hline
\end{tabular}

$* *$ : Statistically significant difference $(p<0.01)$.

Table (5): Comparison between malignant and benign as regards TNM.

\begin{tabular}{|c|c|c|c|c|c|}
\hline \multirow{3}{*}{ TNM } & \multicolumn{4}{|c|}{ Pathology results } & \multirow{3}{*}{$\begin{array}{c}p- \\
\text { value }\end{array}$} \\
\hline & \multicolumn{2}{|c|}{ Malignant } & \multicolumn{2}{|c|}{ Benign } & \\
\hline & No. & $\%$ & No. & $\%$ & \\
\hline T1N0 & 8 & 22.2 & 0 & 0.0 & 0.059 \\
\hline $\mathrm{T} 1 \mathrm{~N} 2$ & 2 & 5.6 & 2 & 50.0 & \\
\hline T2NO & 6 & 16.7 & 0 & 0.0 & \\
\hline $\mathrm{T} 2 \mathrm{~N} 2$ & 2 & 5.6 & 0 & 0.0 & \\
\hline T3NO & 2 & 5.6 & 0 & 0.0 & \\
\hline $\mathrm{T} 3 \mathrm{~N} 1$ & 2 & 5.6 & 2 & 50.0 & \\
\hline T3N2 & 4 & 11.1 & 0 & 0.0 & \\
\hline $\mathrm{T} 3 \mathrm{~N} 3$ & 2 & 5.6 & 0 & 0.0 & \\
\hline T4N0 & 4 & 11.1 & 0 & 0.0 & \\
\hline T4N1 & 2 & 5.6 & 0 & 0.0 & \\
\hline T4N2 & 2 & 5.6 & 0 & 0.0 & \\
\hline
\end{tabular}

Table (6): Comparison between malignant and benign as regards signal intensity on $\mathrm{T} 2$.

\begin{tabular}{|c|c|c|c|c|c|}
\hline \multirow{3}{*}{$\begin{array}{l}\text { Signal intensity } \\
\text { on } \mathrm{T} 2\end{array}$} & \multicolumn{4}{|c|}{ Pathology results } & \multirow{3}{*}{$\begin{array}{c}p- \\
\text { value }\end{array}$} \\
\hline & \multicolumn{2}{|c|}{ Malignant } & \multicolumn{2}{|c|}{ Benign } & \\
\hline & No. & $\%$ & No. & $\%$ & \\
\hline Hyper intense & 32 & 88.9 & 4 & 100.0 & 0.482 \\
\hline ISO intense & 4 & 11.1 & 0 & 0 & \\
\hline
\end{tabular}


Table (7): Comparison between malignant and benign lesions according to the pathology results.

\begin{tabular}{|c|c|c|c|c|c|}
\hline & \multicolumn{4}{|c|}{ Pathology results } & \multirow{3}{*}{$\begin{array}{c}p- \\
\text { value }\end{array}$} \\
\hline & \multicolumn{2}{|c|}{ Malignant } & \multicolumn{2}{|c|}{ Benign } & \\
\hline & No. & $\%$ & No. & $\%$ & \\
\hline \multicolumn{6}{|c|}{ Cartilage invasion: } \\
\hline Yes & 14 & 38.9 & 0 & 0.0 & 0.122 \\
\hline No & 22 & 61.1 & 4 & 100.0 & \\
\hline \multicolumn{6}{|c|}{ Lymph nodes: } \\
\hline Yes & 14 & 38.9 & 4 & 100.0 & $0.020 *$ \\
\hline No & 22 & 61.1 & 0 & 0.0 & \\
\hline \multicolumn{6}{|c|}{ Pre epiglottic: } \\
\hline Yes & 8 & 22.2 & 2 & 50.0 & 0.224 \\
\hline No & 28 & 77.8 & 2 & 50.0 & \\
\hline \multicolumn{6}{|c|}{ Paraglottic: } \\
\hline Yes & 16 & 44.4 & 2 & 50.0 & 0.832 \\
\hline No & 20 & 55.6 & 2 & 50.0 & \\
\hline
\end{tabular}

*: Statistically significant difference $(p<0.05)$.

Table (8): Comparison between malignant and benign as regards diffusion.

\begin{tabular}{lllllll}
\hline \multirow{2}{*}{ Diffusion } & \multicolumn{4}{c}{ Pathology results } \\
\cline { 2 - 3 } & \multicolumn{2}{c}{ Malignant } & & \multicolumn{2}{c}{ Benign } & $p$ - \\
\cline { 2 - 3 } \cline { 5 - 6 } & No. & $\%$ & & No. & $\%$ & \\
\hline Restricted & 30 & 83.3 & & 2 & 50.0 & 0.114 \\
Facilitated & 6 & 16.7 & & 2 & 50.0 & \\
\hline
\end{tabular}

Table (9): Sensitivity, specificity, PPV, NPV and accuracy of MRI dependent on pathology.

\begin{tabular}{lccccc}
\hline & \multicolumn{5}{c}{ Pathology results } \\
\cline { 2 - 6 } & Sensitivity & Specificity & PPV & NPV Accuracy \\
\hline Cartilage invasion & 38.9 & 100.0 & 100.0 & 15.4 & 45.0 \\
Lymph nodes & 38.9 & 0.0 & 77.8 & 0.0 & 35.0 \\
Pre epiglottic & 22.2 & 50.0 & 80.0 & 6.7 & 25.0 \\
Paraglottic & 44.4 & 50.0 & 88.9 & 9.1 & 45.0 \\
Diffusion & 83.3 & 50.0 & 93.8 & 25.0 & 80.0 \\
\hline
\end{tabular}

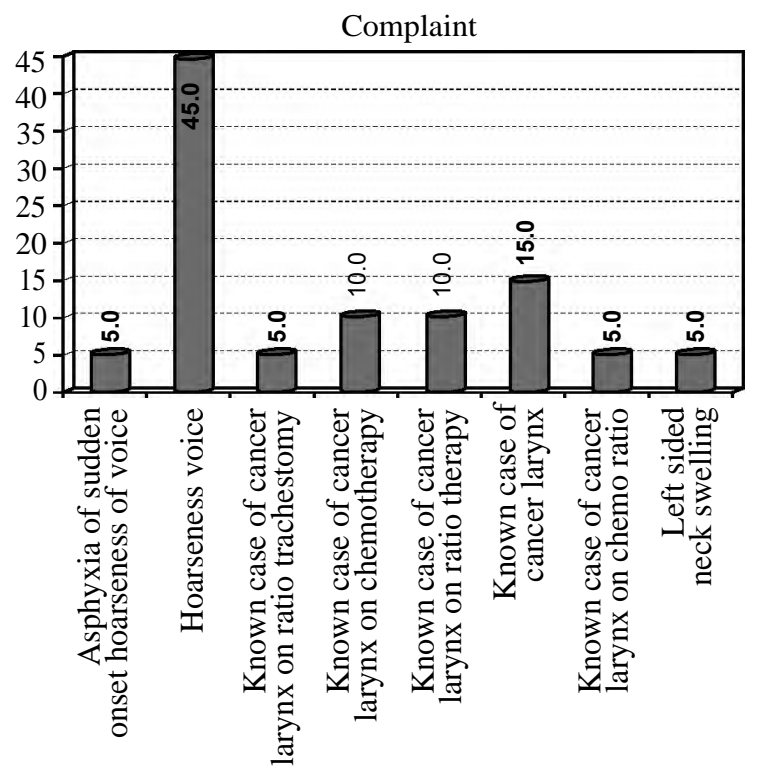

Fig. (4): Symptomatology of the cases.

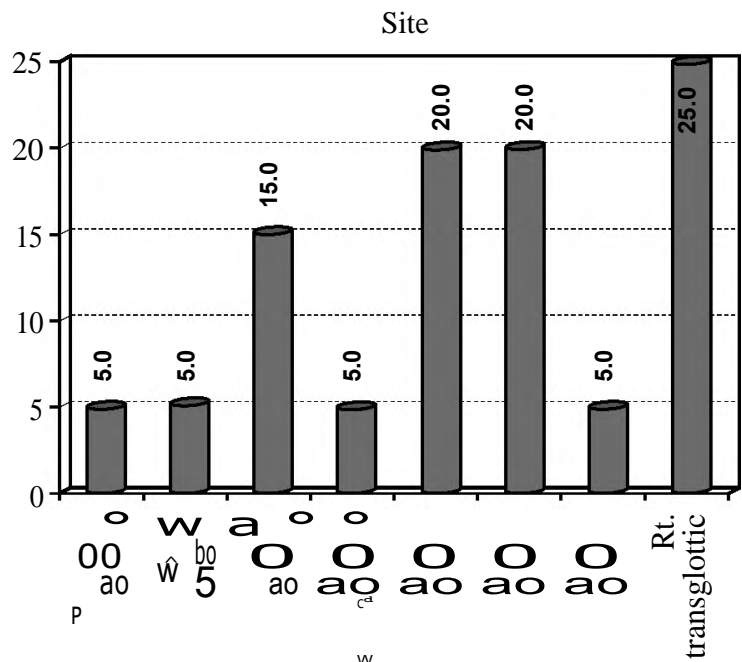

Fig. (5): Classification by the anatomic site.

TNM

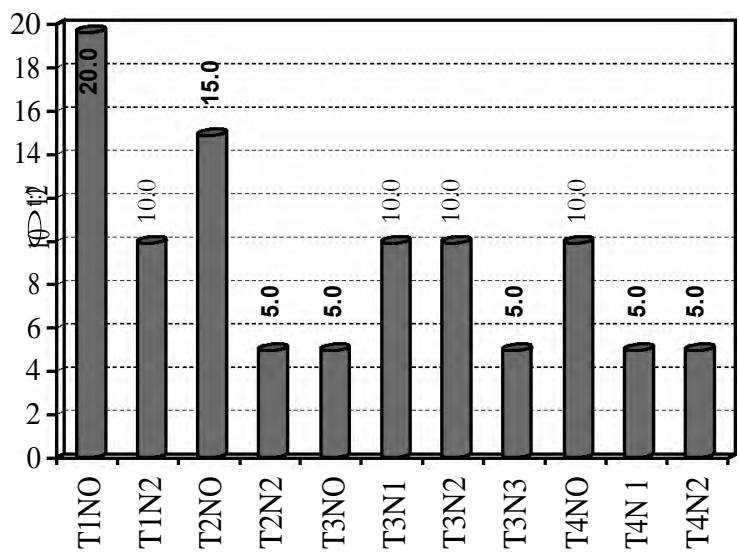

Fig. (6): Local TNM classification of the cases.

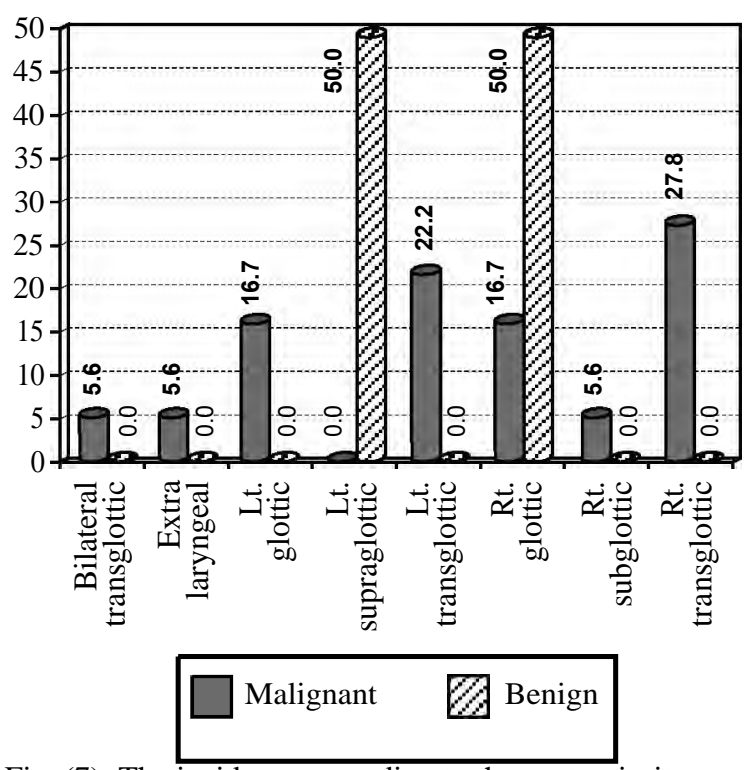

Fig. (7): The incidence according to the anatomicsite. 


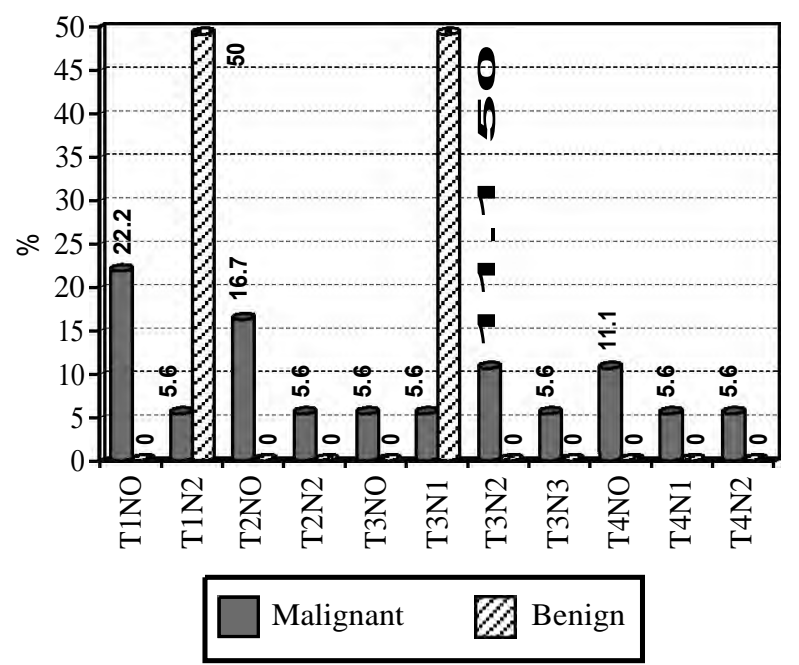

Fig. (8): Local TNM classification.

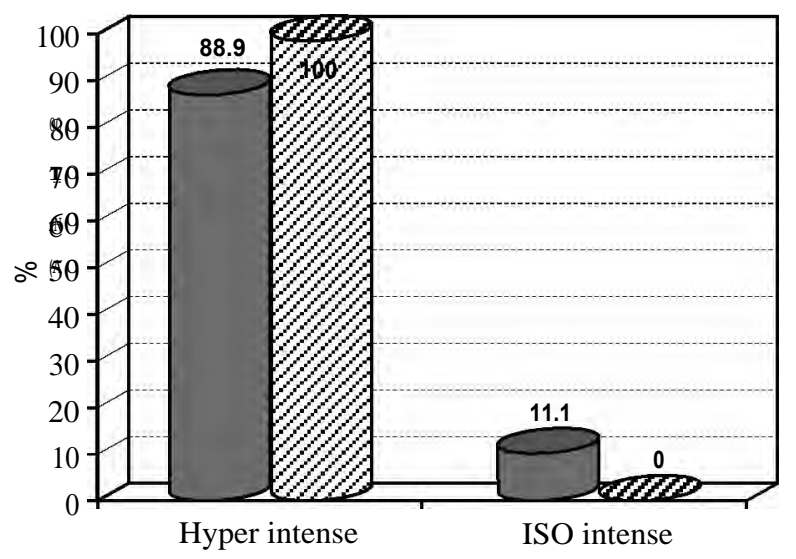

Malignant $Q 2$ Benign

Fig. (9): The signal intensity on T2WI.

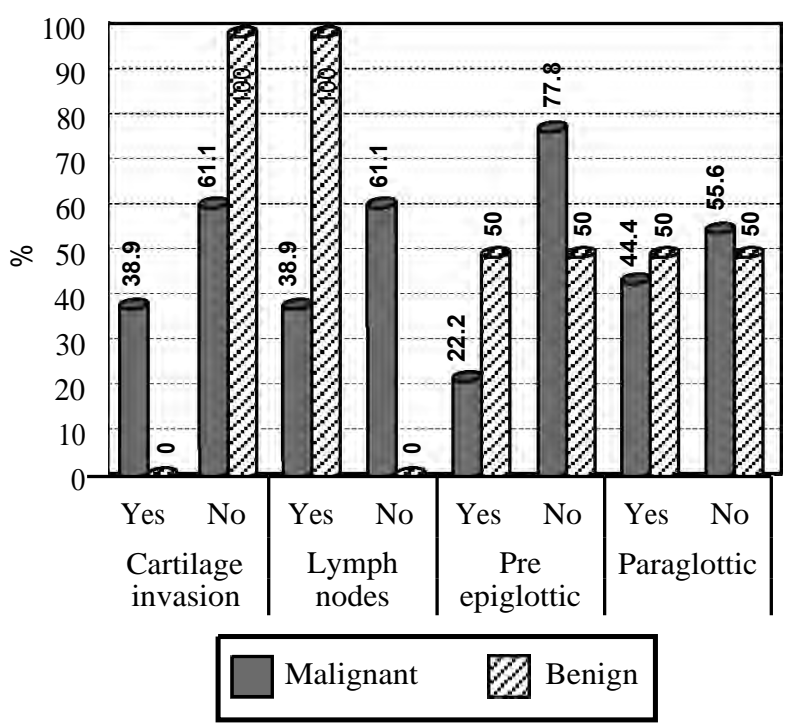

Fig. (10): Variant types of cancer invasions.

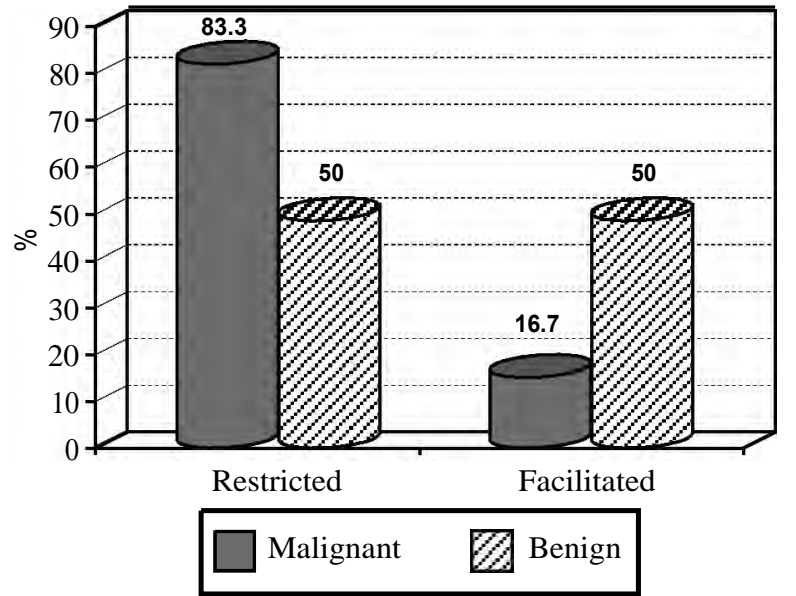

Fig. (11): The diffusion pattern.

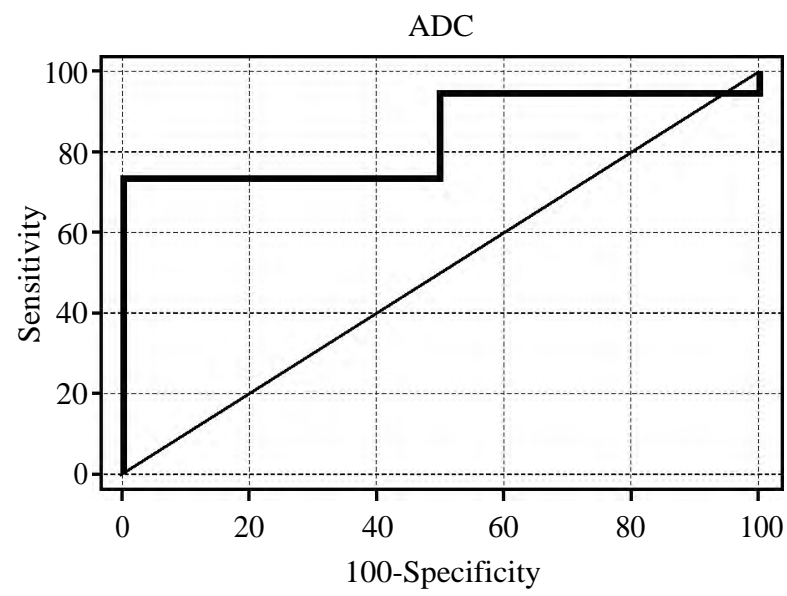

Fig. (12): ROC curve for ADC dependent on pathology results.

\section{Discussion}

The structure of the larynx is complex, with many different tissues, including mucosa, cartilage (ossified or non-ossified), muscle, fat, and air in close proximity, and various physiological movements, including swallowing, breathing, speaking, and impulses arising from major blood vessels. These issues result in distortion and failed fat suppression artifacts that can cause non diagnostic images. Because of these limitations, there was been little use of DWI in the head and neck. To date, there have been few reports about DWI in laryngeal lesions [9]. Most have reported value in detecting recurrent tumors after radiotherapy/ chemotherapy [10]. The use of DWI to discriminate malignant from benign lesions in the head and neck has been investigated in a limited number of studies; however, there is no previous report about the preoperative discrimination of laryngeal carcinomas from precancerous lesions. These limitations have gradually been overcome with steady improvements in MRI techniques [11] driven by a 
wide variety of potential applications. DWI of the head and neck has commonly been done with a 1.5-T scanner. The signal gain at 3.0T improves imaging of the head and neck with respect to spatial resolution and acquisition time in our study, the main clinical presentation was hoarseness of voice in 45\% and this consistent with Singer et al., 1996. This retrospective study evaluates the contribution by MRI in the clinical staging of laryngeal cancer and the choice of therapeutic approach. In particular, MRI shows a sensitivity of $100 \%$ and a specificity of $97 \%$ in assessing areas such as paraglottic space, anterior commissure, thyroid, and arytenoid cartilages, with various indications for conservative surgery. Instead, in our series the accuracy of MRI in T1 stage was $85 \%$, and for laryngoscopy was $85.7 \%$, the accuracy of MRI in T2 stage was $85 \%$, and for laryngoscopy was $80 \%$, the accuracy of MRI in T3 stage was $95 \%$, and for laryngoscopy was $75 \%$ the accuracy of MRI in T4 stage was $100 \%$, and for laryngoscopy was $80 \%$. While for the determination of cartilaginous invasion MR showed a sensitivity $38.9 \%$, specificity $100 \%, 45 \%$ accuracy. The integration of DWI into the magnetic resonance protocol has the potential to increase the specificity $50 \%$, sensitivity $83.3 \%$, accuracy 80 based on these considerations, it is clear in the treatment of early glottic cancer that it is important to identify the involvement of anterior commissure, paraglottic spaces, and laryngeal cartilages: The possible involvement of these deep structures could contraindicate $\mathrm{CO} 2$ laser treatment or radiation, because of its high rate of recurrence or chondro necrosis. Any focal involvement of arytenoid cartilages or paraglottic space and thyroid cartilage requires a more radical treatment, using LSC or MSCL, preserving functional laryngeal functions [12].

In our study, we used b value of $400,600,800$ and $1000 \mathrm{~s} / \mathrm{mm}^{2}$ in the start however later using b value not higher than 1000 produced better quality images and so better results. The cut off value for ADC was $>0.64$, sensitivity was $73.7 \%$, specificity $100 \%$, accuracy was $86.9 \%$. Whilethe ADC values were lower for patients with laryngeal carcinoma (mean $1.19560 .3261023 \mathrm{~mm}^{2} / \mathrm{s}$ ) versus those with laryngealprecancerous lesions (mean $\left.1.78060 .3261023 \mathrm{~mm}^{2} / \mathrm{s} ; p, 0.001\right)$. ROC analysis showed that the area under the curve was 0.956 and the optimum threshold for the ADC was $1.45561023 \mathrm{~mm}^{2} / \mathrm{s}$, resulting in a sensitivity of $94.1 \%$, a specificity of $90.9 \%$, and an accuracy of $92.9 \%$. Consistent with who proved that reduced $\mathrm{ADC}$ values have been reported for most malignant tumors and are thought to be due to cellular membranes impeding the mobility of water protons.
At last, there were some limitations to our study:

First, we are reporting our initial experience.

Second, the relatively short time that was available for collection of patients who fulfill inclusion criteria. This needs further study with a larger number of patients.

Third, DWI in the neck was still limited by technical problems with regard to susceptibility artifacts and low spatial resolution. Technical developments of DWI sequences with advanced coils in the field of > 3T MRI could overcome these disadvantages.

\section{Conclusion:}

The ADC threshold in this preliminary study was $1.45561023 \mathrm{~mm}^{2} / \mathrm{s}$, resulting in a sensitivity of $94.1 \%$, a specificity of $90.9 \%$, and an accuracy of $92.9 \%$. This threshold did not overlap markedly for laryngeal carcinomas and precancerous lesions.

\section{Conflicts of interest:}

No conflict of interest has been declared.

\section{Acknowledgments:}

I would like to express my deepest thanks, gratitude, and appreciation to Prof. Dr. Alaa Kamel Abdel Haleem, professor of Otorhinolaryngology Faculty of Medicine, Assiut University for his constant encouragement, I feel especially profound thanks and extremely grateful to Dr. Nagham Nabil Omar, assistant professor of Radio diagnosis and Dr. Sherif Mohamed Abdel Aal, lecturer of Radio Diagnosis, Faculty of Medicine, Assiut University for their guidance, expert advice and constant support which I feel, I offer my thanks and regards to all staff members and colleges of Radio diagnosis Department, Assiut University.

\section{References}

1- ORTHOLAN C., BENEZERY K., DASSONVILLE O., POISSONNET G., BOZEC A., GUIOCHET N. and BELKACEMI Y.: A specific approach for elderly patients with head and neck cancer, Anticancer Drugs, Vol. 22, No. 27, pp. 647-55, 2011.

2- ALLEGRA E., FRANCO T., TRAPASSO S., DOMANICO R., La BORIA A. and GAROZZO A.: Modified supracricoidlaryngectomy: Oncological and functional outcomes in the elderly," Clinical Interventions in Aging, Vol. 7, pp. 475-80, 2012.

3- LI B., BOBINSKI M., GANDOUR-EDWARDS R., FARWEL D.G. and CHEN A.M.: Overstaging of cartilage invasion by multidetector CT scan for laryngeal cancer and its potential effect on the use of organ preservation with chemoradiationBritish Journal of Radiology, Vol. 84, No. 997, pp. 64-9, 2011. 
4- HARTL D.M., FERLITO A., BRASNU D.M., LANGENDIJK J.A., RINALDO A., SILVER C.E. and WOLF G.T.: Evidence-based review of treatment options for patients with glottic cancer, Head \& Neck, Vol. 33, No. 11, pp. 1638-48, 2011.

5- SHANG D.S., RUAN L.X., ZHOU S.H., BAO Y.Y., CHENG K.J. and WANG Q.Y.: Differentiating Laryngeal Carcinomas from Precursor Lesions by DiffusionWeighted Magnetic Resonance Imaging at 3.0 T: A Preliminary Study.

6- SOBIN L.H., GOSPODAROWICZ M.K. and WITTEKIND C.: TNM Classification of Malignant Tumours, Wiley-Blackwell, Oxford, UK, 7 th edition, 2009.

7- MAROLDI R., RAVANELLI M. and FARINA D.: Magnetic resonance for laryngeal cancer," Current Opinion in Otolaryngology \& Head and Neck Surgery, Vol. 22, No. 2, pp. 131-9, 2014.

8- GREENE F.L.: American Joint Committee on cancer: Larynx. In: Greene F.L., editor. American Joint Committee on cancer: AJCC staging manual. 7 th ed. NY: Springer; p. 57-68, 2010.

9- TSHERING-VOGEL D.W., ZBAEREN P., GERETSCHLAEGER A., VERMATHEN P. and De KEYZER F.: Diffusion-weighted MR imaging including biexponential fitting for the detection of recurrent or residual tumour after (chemo)radiotherapy for laryngeal and hypopharyngeal cancers. Eur. Radio., 23: 562-9, 2013.

10- VANDECAVEYE V., De KEYZER F., VANDER POORTEN V., DERAEDT K. and ALAERTS H.: Evaluation of the larynx for tumour recurrence by diffusionweighted MRI after radiotherapy: Initial experience in four cases. Br. J. Radiol., 79: 681-7, 2006.

11- THOENY H.C.: Diffusion-weighted MRI in head and neck radiology: Applications in oncology. Cancer Imaging, 10: 209-14, 2011

12- GAROZZO A., ALLEGRA E., La BORIA A. and LOMBARDO N.: Modified supracricoidl laryngectomy, Otolaryngology-Head andNeck Surgery, Vol. 142, No. 1, pp. 137-9, 2010.

\section{دور الرثين المغناطيسى فى سرطان الحنجرة}

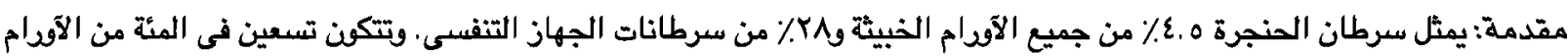

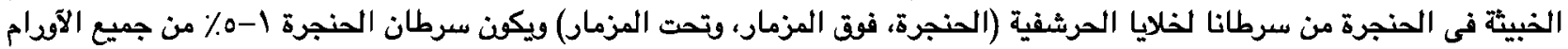

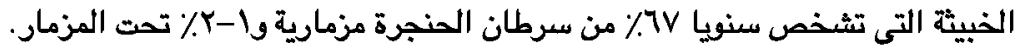
ويعتبر الرنين المغناطيسى آدق من الآثعة المقطعية فى تقييم غزو الآنسجة الرقيقة. الهدف من الدراسة: تقييم دور الرنين المغناطيسى فى سرطان الحنجرة وتقييم مدى دقته فى تحديد مرحلة الوم. المريض وآساليب الفحصر: المريض: إختيار المرضى الذين يعانون من سرطان المنجرة.

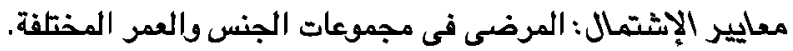

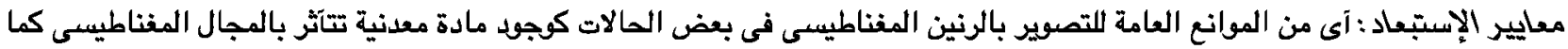

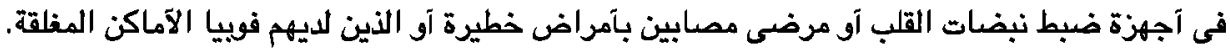

تحضير المريض : للحصل على فحص التصوير بالرنين المفناطيسى يجب إعداد المريض الآعداد الآمثل للإستفادة المثلى من هذه التقنية:

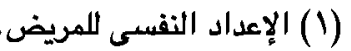

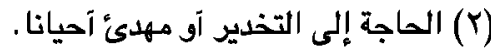

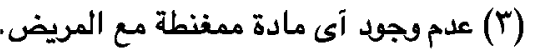

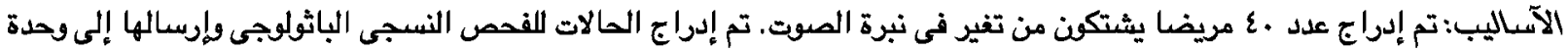
الآثعة لتاكيد النتائج التى تم التوصل إليها بالرنين المغناطيسى بغ بخاصية الإنتشار.

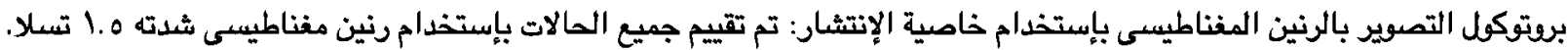

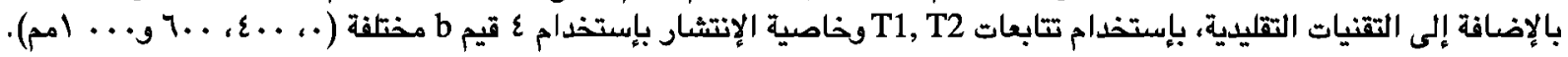
النظر الآخلا فيّة: • تم فحص جميع الحالات بسرية تامة. • تم الصصول على موافقة خطية من كل مريض على هذه الدراسة. 